\title{
How U.S. Public Universities Responded to the COVID-19 Pandemic in March 2020: Lessons Learned from the Variations in Timing of Key Decisions
}

Kevin E. Cevasco

George Mason University

Hayley M. North

George Mason University

Sheryne A. Zeitoun

George Mason University

Abigail F. Gregory

George Mason University

Rachel N. Wofford

George Mason University

Maha H. Hassan

George Mason University

Graham A. Matulis

George Mason University

Aya D. Abdo

George Mason University

Amira A. Roess

George Mason University

David Farris

George Mason University

Michael E von Fricken ( $\square$ mvonfric@gmu.edu )

George Mason University

\section{Research Article}

Keywords: COVID-19, epidemiology, Public university pandemic response, University policy

Posted Date: May 15th, 2020

DOI: https://doi.org/10.21203/rs.3.rs-28634/v1 
License: (c) (i) This work is licensed under a Creative Commons Attribution 4.0 International License. Read Full License 


\section{Abstract}

The timing of the pandemic response decision can affect the national mass migration of millions of students back to campus thus limiting community spread. During the initial stages of the COVID-19 pandemic, universities across the United States were faced with making difficult decisions often without explicit or uniform guidance from state and national leadership. This study examines how and when public universities responded to the U.S. COVID-19 outbreak, regarding decisions to cancel international travel, switch to online learning, transition faculty and staff to remote work, limiting on-campus housing, and implementing campus closures. Data was collected on university timing and decision making for medium to large public universities with more than 5,000 enrolled students, representing 412 institutions, $7 \mathrm{M}$ people, and all 50 states and Puerto Rico, between February 27 and March $31^{\text {st }}$, 2020. Substantial heterogeneity in decision making and the timing of those decisions as they relate to key state, national, and global emergency announcements were observed. The WHO pandemic declaration coincided with announcements to move away from on-campus learning. Universities decisions were made largely at the university level and not coordinated by government agencies, leading to staggered announcements and major variations in university timelines between states and within states. The importance of synchronizing university decisions in a national emergency scenario cannot be understated. Dissonant university decisions and announcement dates may potentially lead to mixed messaging and a reduction of the effectiveness of early interventions. Clear guidance is needed moving forward regarding university operations for fall and summer.

\section{Introduction}

The COVID-19 pandemic, caused by coronavirus SARS-CoV-2, has resulted in almost 2.2 million cases globally and over 670,000 cases in the United States as of April 16 ${ }^{\text {th }}, 2020$ (Dong et al. 2020), and is responsible for unprecedented disruption of higher education. During the initial stages of this pandemic, universities across the United States were faced with making difficult decisions on whether or not to cancel international travel, transfer to online learning, shift faculty/staff to remote work, limit campus housing, and close campus for all non-essential personnel, often without explicit or uniform guidance from state and national leadership. Universities typically rely on government agencies at the federal, state, and local level for guidance on how and when to respond to national emergencies, including public health emergencies. During March of 2020 the Centers for Disease Control and Prevention (CDC), World Health Organization (WHO), Department of Education (ED), Governors, and state and local public health departments provided guidance and directives relevant to pandemic response decision making (CDC 2020b; WHO 2020b). In early March, the CDC sent state and local governments evidence-based mitigation strategy guidance to support locally appropriate decisions to slow the spread of COVID-19, which included social distancing, limiting large gatherings, and prohibiting travel to Italy, South Korea, and China (CDC). These community mitigation strategies were designed to reduce COVID-19 incidence and to protect individuals at increased risk of severe illness, healthcare personnel, and other critical workforces (CDC 2020a). 
At present, while the exact mechanisms of SARS-CoV-2 transmission are still not completely understood, the majority of guidelines aim to reduce person-to-person contact, with nationwide closures of schools $(\mathrm{K}-12)$, universities, retailers, dining establishments, places of worship and other areas where people congregate. Recently, local guidelines have included wearing masks, of any quality, when in public to reduce inhalation of infectious respiratory droplets, which are thought to remain airborne for up to 3 hours following coughing or sneezing by an infected individual (van Doremalen et al. 2020).

A large concern at the university level is the potential role asymptomatic individuals play as carriers of SARS-CoV-2 (Al-Tawfiq 2020; Rothe et al. 2020), with growing evidence suggesting young adults returning from mass gatherings like Mardi Gras, may have contributed to ongoing transmission (CDC COVID-19 Response Team 2020). This was also observed in China, where travelers departing from Wuhan before the Chinese Spring Festival were likely the main infection source for other cities in China (Zhong et al. 2020). The effectiveness of cancelling spring break and other types of travel remains unknow but warrants investigation.

One COVID-19 systematic review of school closures, published early in the pandemic, on April 6th, 2020, indicated that there was no clear research quantifying the contribution of school closures to COVID-19 control (Viner et al. 2020). However, a 2014 UK study concluded that school closures could reduce transmission of pandemic influenza if instituted early in outbreaks (Jackson et al. 2014). Implementing social distancing and closing public spaces, including university settings, will likely reduce the risk of intergenerational transmission from students who could then pass the infection on to high risk family members or others in their social networks (WHO 2020a).

The swift, severe, and global nature of COVID-19 offers an important opportunity to systematically examine and learn from risk communication, mitigation, and decision making at the university level during a global public health emergency. To learn from what happened at the onset of the U.S. COVID-19 outbreak, this study describes timelines in public university decision making for canceling international travel, switching to online learning, transitioning faculty/staff to remote work, limiting on-campus housing, and implementing campus closures. Lessons learned can inform how decisions are standardized and implemented for whether to resume in-person university operations Fall 2020.

\section{Methods}

\section{Study Design}

An original database of COVID-19-related policy changes was compiled, capturing data from 412 U.S. public universities. Data were collected from university COVID-19 webpages and social media presences to capture the chronology of official announcements typically originating from the university president's office. Data included all university announcements made from February 27th through March 31st, 2020. Key university decisions include; canceling international travel, transitioning from in-person to online classes, faculty/employee transition to remote work, university requests for students to depart on-campus 
housing, university students required to vacate student housing, and closing campus to all but essential personnel.

The universities included in this study were selected from the Department of Education Integrated Postsecondary Education Data System (IPEDS) 2018 "First Look Universe" data set

(https://nces.ed.gov/ipeds/datacenter).. IPEDS is a system of interrelated surveys conducted annually by the U.S. Department of Education's National Center for Education Statistics, which gathers information from every college, university, and vocational institution that participates in federal student aid programs. A total of 412 universities in the IPEDS institutional sector were included in this study because they met the following criteria: 5,000 or more enrolled students, publicly funded, four-year institution status, and degree granting (Figure 1).. These universities represent 5,896,001 students and 1,528,782 faculty/staff members. Community colleges, private universities, online only institutions, and vocational programs were excluded. Public universities were of interest because staff are state employees and must adhere to guidelines at state and federal levels, allowing for more transparent and readily available data extraction. Additionally, public universities offer representation for all 50 states. Four-year institution status was of interest because these universities typically operate study abroad programs, conduct international research, admit a high volume of international students, and have on-campus student housing.

COVID-19 state case data were extracted from the 'COVID Tracking Project' website (https://covidtracking.com/),, which reports current, retrospective, and cumulative numbers by state,. This information was then linked to State of Emergency (SOE) announcements and other important global, national, and statewide announcement dates compiled from official government and organization webpages.

\section{Quality Control Methods}

Each survey team member was assigned a list of universities to review, which were populated using IPEDS unique ID numbers, and linked directly to university home webpages. The survey team was provided a guide with various scenarios explaining how to interpret policy and announcements to coordinate interpretations. After the first round of data collection, all universities were reassigned to another team member, compiled again, and compared to initial data collections. Discordance between dates were then examined by study leads and double checked to determine a final designation.

\section{Data Management and Analysis}

Data were entered and managed in Google WorkSheets and Google AppSheet. Descriptive statistics, including range of days between decision dates for individual states and average number of days between decision dates at the state levels were generated using MS Excel, R version 3.6.1 (R Core Team, Vienna, Austria) and Stata version 16 (StataCorp. College Station, TX). Graphs were generated using RStudio version 1.2.5019 (RStudio Inc, Boston, MA) (Wickham 2016). 


\section{Results}

A total of 412 public universities were included in this analysis. Large heterogeneity in public university decision making and the timing of those decisions was observed (Figure 2) as they relate to state and national emergency announcement dates and the WHO declaration of a pandemic. Figure 3 describes total university actions over time, with key dates overlain. In brief, the first documented community acquired case in the U.S. occurred in California on February 26th, 2020. On March 5th, the Department of Education issued guidance for interruptions of study related to COVID-19. This announcement addressed concerns expressed by higher education leaders regarding how they should comply with Title IV of the Higher Education Act. The guidance relieved the university of many regulatory and financial liabilities for pandemic response actions and created a landscape where universities could act independently. The guidance addresses scenarios where universities temporarily stop offering in-person classes in order to prevent the spread of COVID-19. Several universities in Washington state announced a shift to online learning early the next day due to concerns of increased local transmission.

Universities then began cancelling international study abroad programs and university-sponsored travel as early as March 2nd, with more than $50 \%$ canceling international travel by March 11, 2020, the day the WHO declared that COVID-19 was a pandemic. All universities that had available data reporting study abroad, reported international travel cancelations by March 20. In general, universities quickly announced moving in-person courses to online learning, with all universities making announcements between March 4 and March 20, with 77\% (318/412) of universities making announcements before March 13, 2020, the day of the National emergency declaration. Protocols were rapidly developed by most universities and online learning implementation began, on average, 11 days (0-26 days) after announcements were made by universities. Roughly $86 \%$ (356/412) of universities announced that they were discouraging students from returning to on-campus housing between March 9th and March 27th. By March 31st, 59\% (244/412) of universities had released vacate campus housing orders on an exception only basis in 59\% (391/412) of universities. Furthermore, $81 \%$ (333/412) of universities suspended classes temporarily to prepare for online learning and $95 \%$ canceled international travel, with cancellations announced between February 25th and March 23rd. Details by state, including the case count of COVID-19 on SOE dates, the average number of days after the SOE was declared for universities to make announcements regarding transitioning to online learning and campus closures, and the corresponding case counts of COVID-19 by state for those decision dates, can be found on Table 1 .

Timing of university decisions are compared against the backdrop of the movement of 5.6M students during spring break. The WHO pandemic declaration on March 11th, coincided with a large group of universities cancelling in-person classes. Most universities implemented pandemic response plans on March 11th and 12th, including announcements that transitioned in-person classes to online learning, and discouraged students from staying and/or returning to on-campus housing. The timing of the online learning and housing decisions allowed many universities to avoid a national mass migration of millions of students back to campus, thus limiting community spread. During the COVID-19 pandemic, the WHO 
pandemic declaration coincided with the move away from on-campus learning and may have provided a political backstop for decision makers (Navarro et al. 2016).

The decisions to close campuses, cancel international travel, and limit on-campus housing were distributed over time without a clear association to key decision dates, and were likely subject to individual university leadership decisions, state and local guidance, and local COVID-19 prevalence. The campus closure timeline also followed spring break periods, typically occurring one week after spring break. Graphical depictions of the national prevalence of COVID-19, overlain on specific types of university decision dates, can be found in Figure S1 (Online Resource).

\section{Discussion}

University pandemic mitigation decisions vary widely between states and within states. Decisions do not align clearly with state or national emergency announcements, as seen with university announcements to transition from in-person to online learning coinciding frequently with the WHO pandemic declaration, with implementation dates of online learning typically beginning at the end of spring break schedules.

Our findings suggest that previously identified gaps in pandemic policy and planning at public universities continue to be an issue. In 2006, the University of Washington conducted a tabletop exercise to assess existing influenza pandemic response plans and policies (Beaton et al. 2007). A key finding of the report was that specific "triggers" were not identified that would lead to implementing social distancing. Gaps were found in plans and policies for isolation and quarantine, continuity of operations, disaster mental health services, integration of volunteers into disaster response, tracking the travel of university students and personnel, communication problems, and ways to meet the needs of the resident and foreign students and faculty during an outbreak (Beaton et al. 2007). Government policy and regulation both impact how universities prepare for and execute responses to pandemics. Clear and concise leadership is needed at the state and federal level, given that they control student financial aid, university funding, and accreditation of programs, and have the regulatory tools necessary to elicit immediate action during emergencies.

Examples exist from the H1N1 pandemic influenza response that may provide guidance to build upon. The 'Community Preventive Services Task Force's, Community Guide' recommends pre-emptive, coordinated school dismissals during a severe influenza pandemic based on sufficient evidence of effectiveness in reducing or delaying the spread of infection and illness within communities (The Community Guide). Studies show that early implementation of school closures can reduce cases of influenza (Navarro et al. 2016), and likely holds true for coronaviruses (E. J. Schwartz et al. 2015). The Community Guide recommendations suit the COVID-19 pandemic because it states that across pandemic scenarios with elevated rates of severe illness, the potential benefits school dismissals and community actions may be limited to slowing transmission of infection and reducing peak burden of illness on health care resources. 
Overall, most universities do not have pandemic preparedness plans to aid their response decisions, which may delay decisions as governance and policy issues are addressed (R. D. Schwartz and Bayles 2012). Decisions may also be dependent on temporary government regulatory relief from agencies that control funding and program compliance. Positive COVID-19 cases on campus or in neighboring communities likely increase the sense of urgency. International exposure risk through study abroad programs and an international student base may also drive early conversations about response actions.

Government policy and public health warnings have significant influence on universities implementation of pandemic response actions. Given the important role COVID-19 asymptomatic transmission, university decisions may have had a significant impact on national community spread since most closed in relation to scheduled spring breaks that happened to be during March. Had the pandemic started earlier in the U.S. and closures were forced weeks prior to spring break, universities would have faced an even greater logistical challenge, requiring students to vacate campus rather than the "do not return to campus announcements" that were issued in tandem with extended spring breaks. Alternatively, if the pandemic had emerged earlier and universities decided to keep closures around spring break from a business perspective, it is entirely possible that students would have left universities as major vehicles of transmission and geographic spread. In short, university systems were fortunate that closures aligned with spring break where many students had already left campus. Lessons from the shutdown of universities in response to COVID-19 must be learned now so that stakeholders can make better informed decisions about how and when universities can transition back to on-campus operations.

Our study was limited to public institutions because they respond directly to state budgets and decisionmaking guidelines. Data was also subject to ambiguity in mandatory versus suggested university actions, however, quality control checks allowed us to reach a consensus on announcement types and effective dates. Furthermore, different spring break calendars likely played a role in decision making timelines, which could have forced some universities to respond early or late depending on situational urgency, warranting a deeper analysis. Finally, all data extracted from official announcements only captures information that was publicly shared, which may have resulted in an underrepresentation of decisions communicated by email only. When specific dates were not included on announcement pages, efforts were made to confirm dates by conducting internet and social media searches. Nevertheless, the results indicate that universities decisions were made largely at the university level and not mandated or coordinated by government agencies, leading to staggered announcements and major variations in decision timelines between states and within states.

\section{Conclusion}

Understanding university responses to COVID-19 is essential to capturing baseline decisions and developing national plans that emphasize a balanced and standardized set of guidelines for resumption of operations in the coming months. The importance of coordinating university decisions in an emergency scenario cannot be understated, with stark variations in university decisions and announcement dates potentially leading to mixed messaging and a reduction of the effectiveness of 
early interventions. Further analysis is needed to examine what other variables are contributing to differences in university decision making at the state and national level. This is especially important given that there will likely be outbreaks into the fall, when universities are keen to resume in-person operations.

\section{Declarations}

Competing interests: The authors declare no competing interests.

\section{References}

1. Al-Tawfiq, J. A. (2020). Asymptomatic coronavirus infection: MERS-CoV and SARS-CoV-2 (COVID19). Travel Medicine and Infectious Disease, doi:10.1016/j.tmaid.2020.101608.

2. Beaton, R., Stergachis, A., Thompson, J., Osaki, C., Johnson, C., Charvat, S. J., et al. (2007). Pandemic policy and planning considerations for universities: findings from a tabletop exercise. Biosecur Bioterror, 5(4), 327-334, doi:10.1089/bsp.2007.0029.

3. CDC's Recommendations for the next 30 days of Mitigation Strategies for Seattle-King, Pierce, and Snohomish Counties based on current situation with widespread COVID-19 transmission and affected health care facilities. Centers for Disease Control and Prevention.

4. CDC (2020a). Implementation of Mitigation Strategies for Communities with Local COVID-19 Transmission. Centers for Disease Control and Prevention.

5. CDC (2020b). Interim Guidance for Administrators of U.S. Institutions of Higher Education. website: Centers for Disease Control and Prevention.

6. CDC COVID-19 Response Team (2020). Geographic Differences in COVID-19 Cases, Deaths, and Incidence - United States, February 12-April 7, 2020. MMWR Morb Mortal Wkly Rep, 69(15), 465-471, doi:10.15585/mmwr.mm6915e4.

7. Dong, E., Du, H., \& Gardner, L. (2020). An interactive web-based dashboard to track COVID-19 in real time. Lancet Infect Dis, doi:10.1016/S1473-3099(20)30120-1.

8. Jackson, C., Mangtani, P., Hawker, J., Olowokure, B., \& Vynnycky, E. (2014). The effects of school closures on influenza outbreaks and pandemics: systematic review of simulation studies. PLOS One, 9(5), e97297, doi:10.1371/journal.pone.0097297.

9. Navarro, J. A., Kohl, K. S., Cetron, M. S., \& Markel, H. (2016). A Tale of Many Cities: A Contemporary Historical Study of the Implementation of School Closures during the 2009 pA(H1N1) Influenza Pandemic. J Health Polit Policy Law, 41(3), 393-421, doi:10.1215/03616878-3523958.

10. Rothe, C., Schunk, M., Sothmann, P., Bretzel, G., Froeschl, G., Wallrauch, C., et al. (2020). Transmission of 2019-nCoV Infection from an Asymptomatic Contact in Germany. N Engl J Med, 382(10), 970-971, doi:10.1056/NEJMc2001468.

11. Schwartz, E. J., Morgan, M., \& Lapin, S. (2015). Pandemic 2009 H1N1 influenza in two settings in a small community: the workplace and the university campus. Epidemiol Infect, 143(8), 1606-1609, 
doi:10.1017/s0950268814002684.

12. Schwartz, R. D., \& Bayles, B. R. (2012). US university response to H1N1: a study of access to online preparedness and response information. Am J Infect Control, 40(2), 170-174, doi:10.1016/j.ajic.2011.02.021.

13. The Community Guide Emergency Preparedness and Response: School Dismissals to Reduce Tranmission of Pandemic Influenza. https://www.thecommunityguide.org/findings/emergencypreparedness-and-response-school-dismissals-reduce-transmission-pandemic-influenza. Accessed March 312020.

14. van Doremalen, N., Bushmaker, T., Morris, D. H., Holbrook, M. G., Gamble, A., Williamson, B. N., et al. (2020). Aerosol and Surface Stability of SARS-CoV-2 as Compared with SARS-CoV-1. N Engl J Med, 382(16), 1564-1567, doi:10.1056/NEJMc2004973.

15. Viner, R. M., Russell, S. J., Croker, H., Packer, J., Ward, J., Stansfield, C., et al. (2020). School closure and management practices during coronavirus outbreaks including COVID-19: a rapid systematic review. Lancet Child Adolesc Health, doi:10.1016/s2352-4642(20)30095-x.

16. WHO (2020a). Q\&A: Similarities and differences - COVID-19 and influenza. https://www.who.int/news-room/q-a-detail/q-a-similarities-and-differences-covid-19-and-influenza. Accessed March 312020.

17. WHO (2020b). WHO Directo-General's opening remarks at the media briefing on COVID-19 - 11 March 2020 https://www.who.int/dg/speeches/detail/who-director-general-s-opening-remarks-at-the-mediabriefing-on-covid-19--11-march-2020. Accessed March 312020.

18. Wickham, H. (2016). ggplot2: Elegant Graphics for Data Analysis. https://ggplot2.tidyverse.org. Accessed March 312020.

19. Zhong, P., Guo, S., \& Chen, T. (2020). Correlation between travellers departing from Wuhan before the Spring Festival and subsequent spread of COVID-19 to all provinces in China. J Travel Med, doi:10.1093/jtm/taaa036.

\section{Table}

Due to technical limitations, Table 1 is provided in the Supplementary Files section.

\section{Supplementary Figure Legend}

Figure S1. Further detail on specific types of university decisions overlain on top of national COVID-19 prevalence.

\section{Figures}




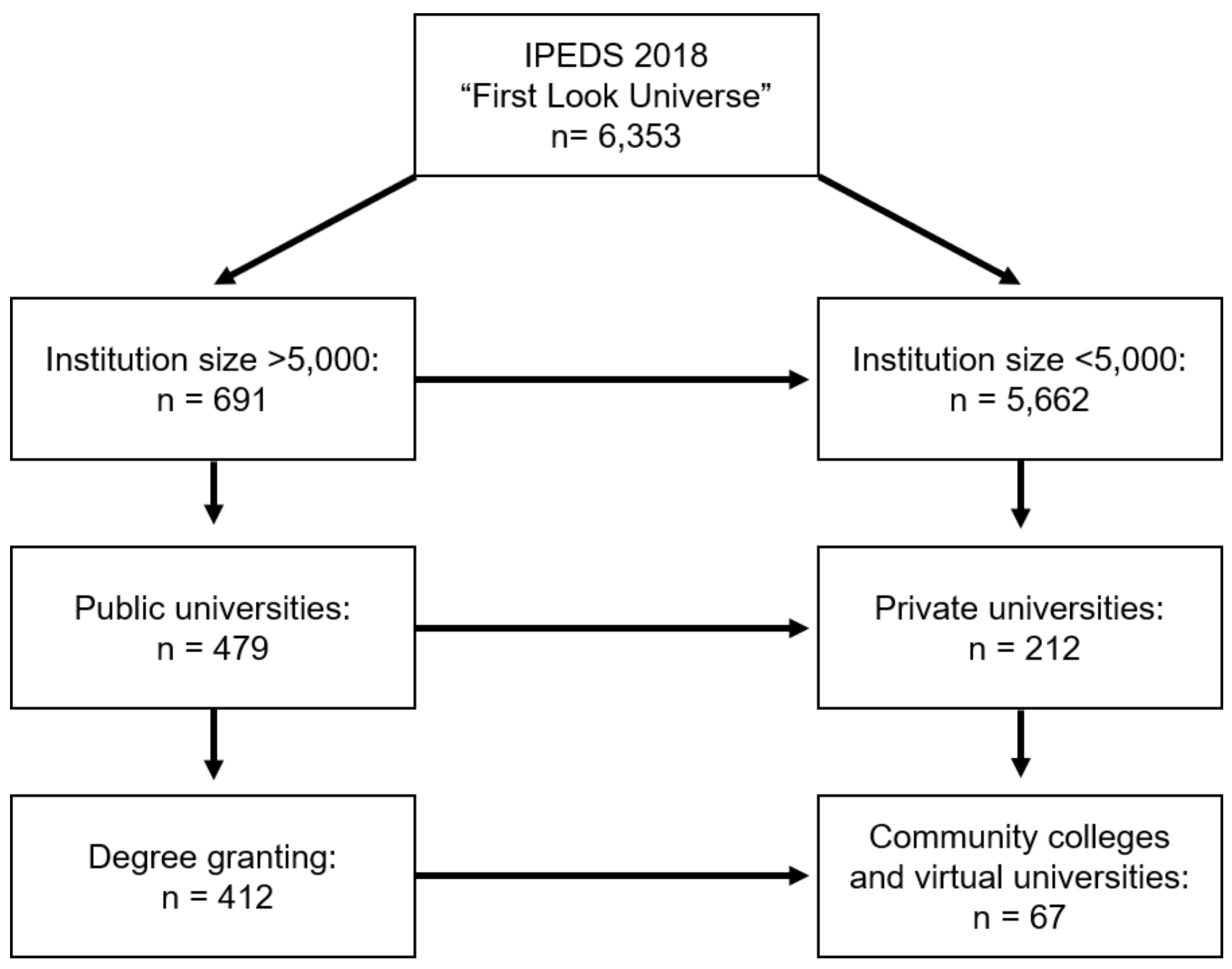

Figure 1

Flowchart of inclusion exclusion criteria. University inclusion criteria from the IPEDS 2018 "First Look Universe" data set 
Online Learning Decision and State of Emergency Declaration

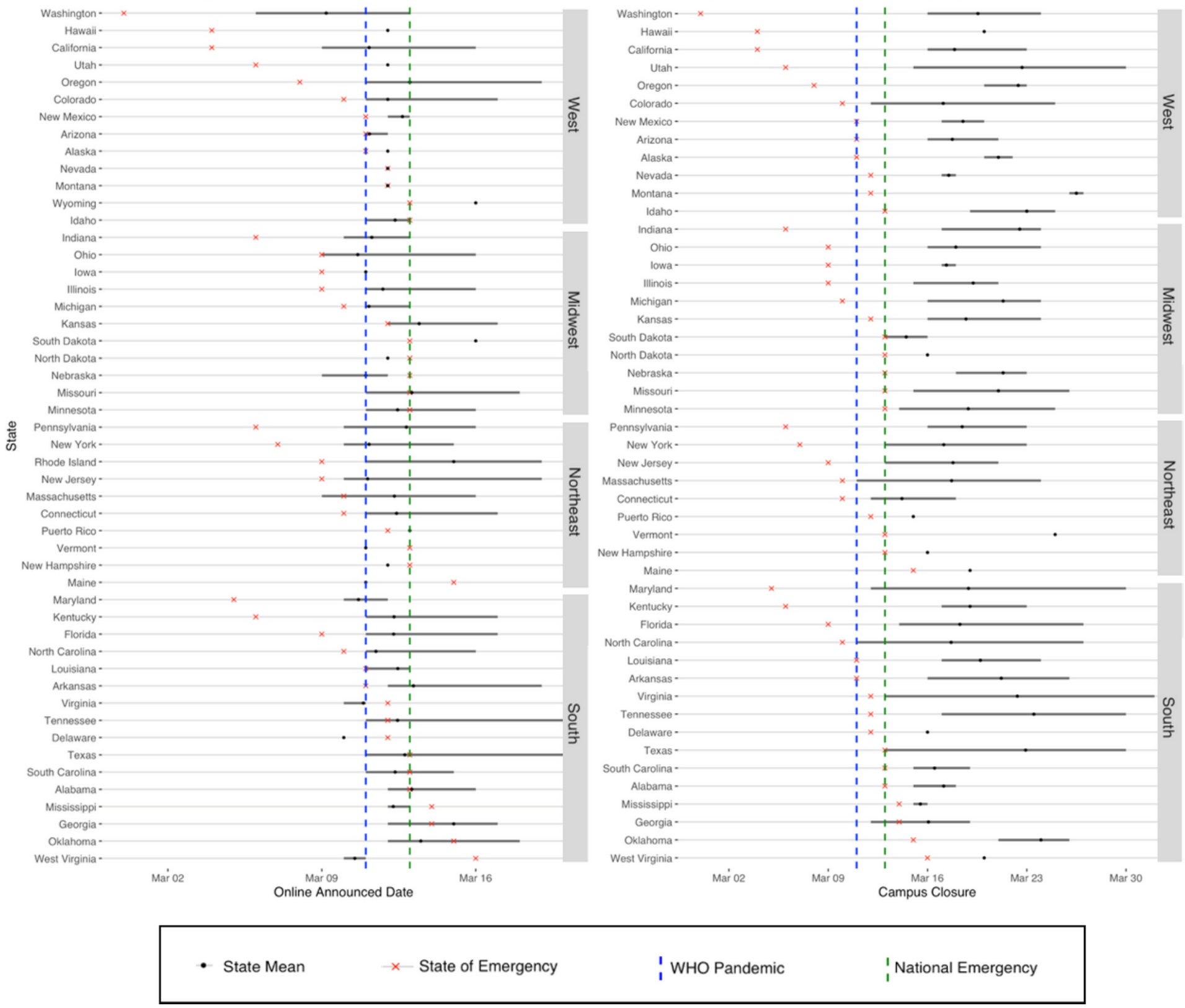

Figure 2

Forest plots of decisions to move course delivery online and close campus based on State of Emergency declarations by State. The forest plots above demonstrate the discordance between states of emergency and university decision making for online distance learning and campus closure (essential personnel only). 


\section{U.S. Public Universities' COVID-19 Response Actions (Feb 25 - Mar 31)}

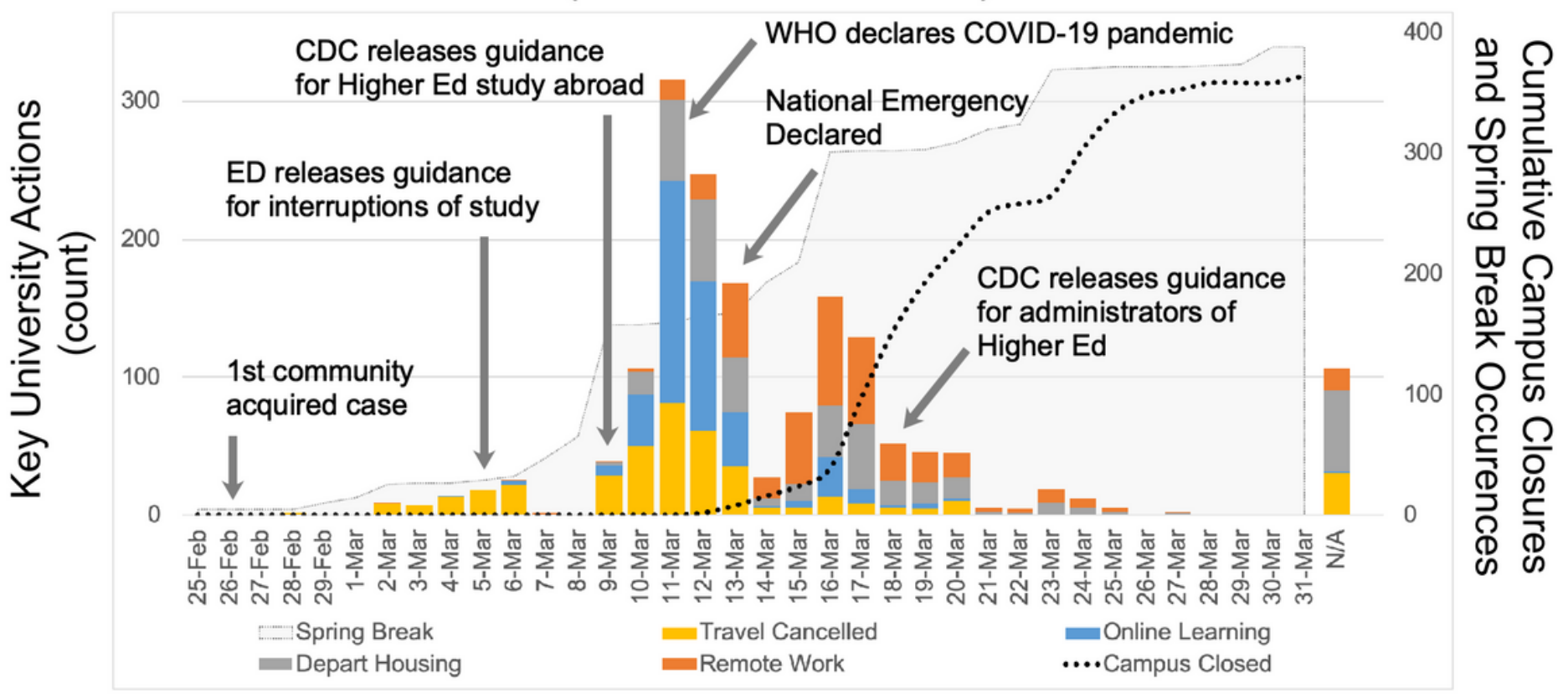

Figure 3

U.S. public universities' actions in response to COVID-19 shown by a stacked histogram over the study period. The N/A bar on the right represents universities with no evidence or available date of implementing pandemic responses in the identified categories. Cumulative beginning of spring break is provided in the background, as it represents important geographic migration of the study population.

\section{Supplementary Files}

This is a list of supplementary files associated with this preprint. Click to download.

- ESM1.tif

- Table1.tiff 